\title{
The Receptor for Advanced Glycation End Products (RAGE) and the Lung
}

\author{
Stephen T. Buckley and Carsten Ehrhardt \\ School of Pharmacy and Pharmaceutical Sciences, Trinity College Dublin, Dublin 2, Ireland \\ Correspondence should be addressed to Carsten Ehrhardt, ehrhardc@tcd.ie
}

Received 7 August 2009; Revised 27 September 2009; Accepted 9 October 2009

Academic Editor: Karl Chai

Copyright ( $) 2010$ S. T. Buckley and C. Ehrhardt. This is an open access article distributed under the Creative Commons Attribution License, which permits unrestricted use, distribution, and reproduction in any medium, provided the original work is properly cited.

\begin{abstract}
The receptor for advanced glycation end products (RAGE) is a member of the immunoglobulin superfamily of cell surface molecules. As a pattern-recognition receptor capable of binding a diverse range of ligands, it is typically expressed at low levels under normal physiological conditions in the majority of tissues. In contrast, the lung exhibits high basal level expression of RAGE localised primarily in alveolar type I (ATI) cells, suggesting a potentially important role for the receptor in maintaining lung homeostasis. Indeed, disruption of RAGE levels has been implicated in the pathogenesis of a variety of pulmonary disorders including cancer and fibrosis. Furthermore, its soluble isoforms, sRAGE, which act as decoy receptors, have been shown to be a useful marker of ATI cell injury. Whilst RAGE undoubtedly plays an important role in the biology of the lung, it remains unclear as to the exact nature of this contribution under both physiological and pathological conditions.
\end{abstract}

\section{Introduction}

The receptor for advanced glycation end products (RAGE) is a member of the immunoglobulin superfamily [1]. The receptor itself is composed of an extracellular region containing one "V"-type and two " $\mathrm{C}$ "-type immunoglobulin domains. This is followed by a hydrophobic transmembranespanning domain which in turn neighbours a highly charged, short cytoplasmic domain that is essential for post-RAGE signalling (Figure 1). This has been termed "full-length" or membrane RAGE (mRAGE). In addition, a number of isoforms have been identified (see below).

RAGE was initially identified and characterised for its ability to bind advanced glycation end products (AGEs), adducts formed by glycoxidation that accumulate in disorders such as diabetes [2]. Subsequently, RAGE has also been shown to be a pattern recognition receptor, recognising families of ligands rather than a single polypeptide. Such ligands include amyloid fibrils, amphoterins, S100/calgranulins, and Mac-1 [3, 4].

In the majority of healthy adult tissues, RAGE is expressed at a low basal level. The up-regulation of RAGE has been associated with a diverse range of pathological events, from atherosclerosis to Alzheimer's disease [5]. However, the exact function of RAGE in the lung has yet to be fully characterised. Uniquely, pulmonary tissues express remarkably high basal levels of RAGE suggesting that RAGE may have a number of functions in the lung distinct from that which it holds in other tissues (Figure 2). Whilst the current body of research indicates important roles in both pulmonary physiology and numerous pathological states, additional work is required to clarify those inconsistencies which currently exist in the literature and further elucidate the important role of RAGE in the lung. This review aims to critically assess the current body of evidence relating to RAGE in the lung and stimulate further research and discussion on its functions in the pulmonary context.

\section{RAGE Isoforms}

In addition to its full-length, membrane-bound form (mRAGE), an increasing number of isoforms of RAGE have been identified (Figure 1). In particular, RAGE has been shown to exist in a soluble isoform termed soluble RAGE (sRAGE). Whilst the sRAGE isoform contains the same 


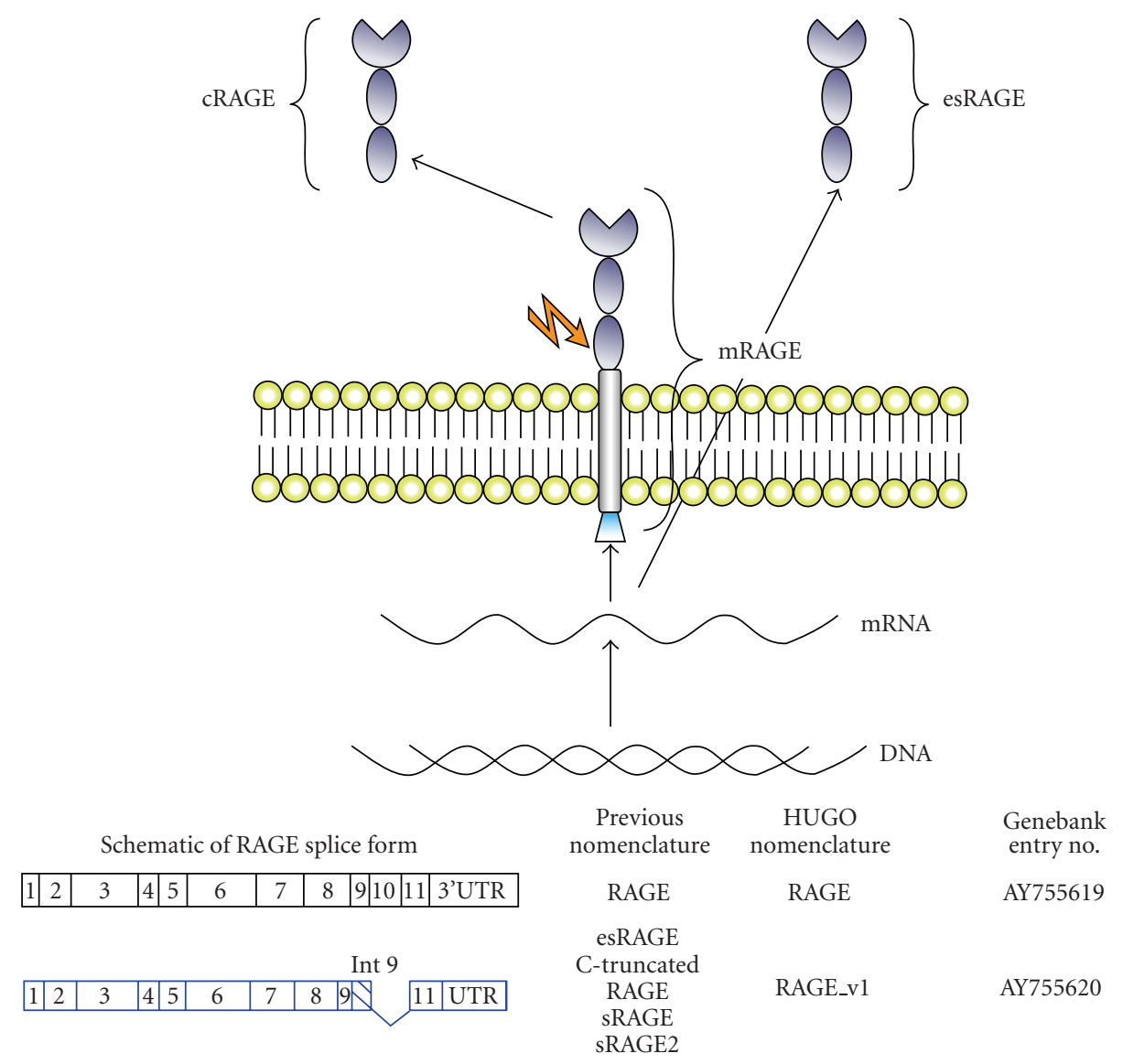

FIGURE 1: Schematic representation of RAGE and the generation of some of its isoforms commonly found in the lung. In addition to its full-length form (mRAGE), RAGE also exists in a soluble form (sRAGE) which lacks the transmembrane and cytosolic domains found in mRAGE. Production of sRAGE isoforms is via either proteolytic cleavage, which gives rise to cleaved RAGE (cRAGE) or alternative splicing at exon 9 resulting in a C-truncated form termed endogenous secretory RAGE (esRAGE).

V-type and C-type regions found in mRAGE, it lacks the transmembrane and cytosolic domains. Consequently, sRAGE is found in the extracellular space and is capable of binding RAGE ligands prior to their interaction with mRAGE. sRAGE is produced primarily by two mechanisms: removal of the transmembrane region via alternative splicing and cleavage from the membrane by proteolysis.

Studies have illustrated that alternative splicing at exon 9 gives rise to a C-truncated form termed endogenous secretory RAGE (esRAGE or RAGE_v1) [6]. Proteolytic cleavage at the cell surface results in the production of a further soluble isoform termed cleaved RAGE (cRAGE) [7]. Recent findings by Raucci et al. [8] suggest that this process is mediated by ADAM10, a membrane metallopeptidase. Notably, both soluble isoforms are capable of binding the same RAGE ligands and in this sense their functions are equivalent. In this way, it has been proposed that sRAGE acts as a decoy receptor, preventing the interaction of mRAGE with its ligands.

Furthermore, it has been shown that the expression of many isoforms in tissues or cell lines is dependent on the cell type. Indeed, Gefter and colleagues [9] have recently illustrated that certain lung isoforms possess distinct epitopes which were not found elsewhere. Interestingly, nonlung cells and tissues were found to express mRNA which was more than three times the size of that expressed in the lung. Moreover, the majority of cell lines were revealed to express a cell line isoform whilst lacking the isoform found predominantly in the lung. These findings suggest that those RAGE isoforms unique to the lung may exhibit both structural and functional differences. However, it is currently unclear as to the specific mechanisms which give rise to any lung-restricted isoforms. Undoubtedly, the role of RAGE under both physiological and pathological settings involves elaborate interaction between the numerous isoforms. Thus, further elucidation of the expression of all isoforms of RAGE is essential.

\section{Localisation and Physiological Role of RAGE in the Lung}

Initial immunostaining data of bovine tissues showed RAGE to be expressed in pulmonary endothelium, bronchial and vascular smooth muscle, alveolar macrophages, leiomyocytes, and the visceral pleural surface [10]. Using polyclonal antibodies and specimens from human thoracoscopy, 


\begin{tabular}{|c|c|}
\hline Adipose tissue & 0 \\
\hline Adrenal gland & 0 \\
\hline Ascites & 0 \\
\hline Bladder & 0 \\
\hline Blood & 0 \\
\hline Bone & 0 \\
\hline Bone marrow & 0 \\
\hline Brain & 0 \\
\hline Cervix & 0 \\
\hline Connective tissue & 26 \\
\hline Ear & 61 \\
\hline Embryonic tissue & 4 \\
\hline Eye & 18 \\
\hline Heart & 33 \\
\hline Intestine & 4 \\
\hline Kidney & 0 \\
\hline Larynx & 0 \\
\hline Liver & 0 \\
\hline Lung & 144 \\
\hline Lymph & 0 \\
\hline Lymph node & 32 \\
\hline Mammary gland & 12 \\
\hline Mouth & 0 \\
\hline Muscle & 0 \\
\hline Nerve & 0 \\
\hline Oesophagus & 0 \\
\hline Ovary & 9 \\
\hline Pancreas & 9 \\
\hline Parathyroid & 0 \\
\hline Pharynx & 0 \\
\hline Pituitary gland & 0 \\
\hline Placenta & 0 \\
\hline Prostate & 10 \\
\hline Salivary gland & 0 \\
\hline Skin & 0 \\
\hline Spleen & 0 \\
\hline Stomach & 10 \\
\hline Testis & 6 \\
\hline Thymus & 12 \\
\hline Thyroid & 0 \\
\hline Tonsil & 0 \\
\hline Trachea & 0 \\
\hline Umbilical cord & 0 \\
\hline Uterus & 0 \\
\hline Vascular & 0 \\
\hline
\end{tabular}

(a)

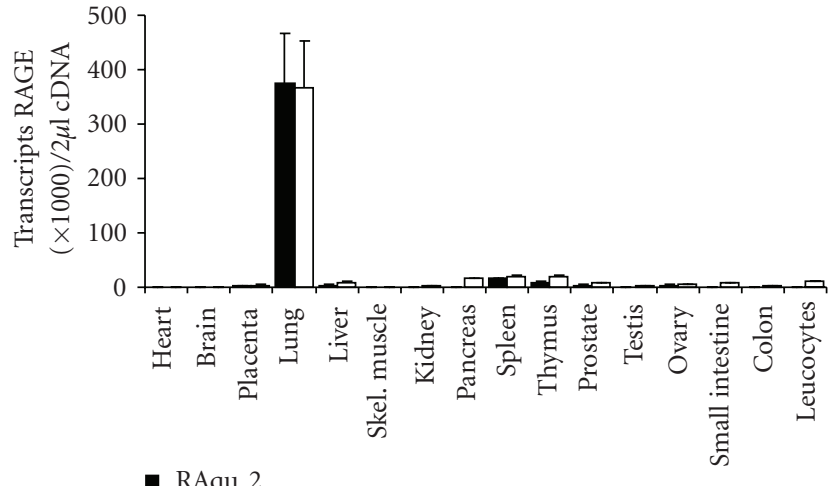

口 RAqu_3

(b)

Figure 2: Tissue distribution of RAGE. (a) Relative number of expressed-sequence clones per million identified in tissue and species-specific databases [11]. The table was updated on 07/20/09. (b) Quantitative analysis of RAGE mRNA expression in healthy human tissue. Two sets of RAGE-specific primers, RAqu_2 (black) and RAqu_3 (white), were used to compare RAGE expression in 16 human tissues of healthy donors in quantitative RT-PCR analysis. The transcript numbers of RAGE were compared with the transcript numbers of GAPDH in $2 \mu \mathrm{L}$ cDNA. The mean and SEM of two separate light cycler runs are displayed (adapted from [12]).

Morbini and coworkers [13] later observed RAGE in bronchiolar epithelia, alveolar type II cells, macrophages, and some endothelia. However, in both rat and human lungs, RAGE has also been suggested to colocalise with markers specific to type I alveolar epithelial cells $[12,14]$. However, this contrasts with Katsuoka's findings [15] that RAGE mRNA expression was predominantly restricted to alveolar type II (ATII) pneumocytes in rats. Expression of both RAGE protein and mRNA in A549, a human lung adenocarcinoma cell line with alveolar type II-like properties, has been suggested by some groups $[16,17]$, while others were unable to confirm RAGE to be present in A549 cells at baseline (Nina Demling personal communication).
Further supporting evidence for the localisation of RAGE to alveolar epithelial type I (ATI) cells was provided by Dahlin et al. [18] who illustrated that RAGE was differentially expressed in rat type I cells. Similarly, the rat type I-like cell line, R3/1, has also been shown to express high levels of RAGE [19]. Collectively, this suggests RAGE being a marker for type I pneumocytes rather than the type II phenotype.

Within the ATI cell, RAGE has been shown to be specifically localised towards the basal cell membrane [12, 14, 20]. Given its high expression in the lung and specific localisation in ATI cells, an important role for RAGE in maintaining lung homeostasis is likely. However, the exact role of RAGE in lung physiology has yet to be fully elucidated. 
Demling and coworkers [12] have shown that HEK293 cells overexpressing RAGE adhere much faster to collagen IV, and to a greater extent when compared to mock transfected cells. Furthermore, the degree of adherence was decreased in the presence of an anti-RAGE antibody. Similarly, in A549 cells, blockade of RAGE inhibited the adhesion onto collagen and intact extracellular matrix [17]. Preincubation with sRAGE was found to reduce this effect, although alone it was found to have no effect on cell adhesion, suggesting that this function is mediated by RAGE in its full-length form. Moreover, expression of RAGE has also been shown to promote spreading of adherent cells on collagen IV. The specificity of this RAGE-collagen IV interaction was underlined by the fact that adherence on fibronectin and laminin was inefficient [12]. In addition, the findings of Bartling et al. [21] that RAGE-transfected lung cancer cells exhibited epithelial growth on collagen layers suggest that this interaction is of functional importance. Most recently, it has been shown that RAGE and collagen IV are colocalised at the basement membrane of normal mouse lungs [22]. Observations by Hori et al. [23] that a RAGE-amphoterin interaction is involved in neurite outgrowth during brain development further support a possible role for RAGE in cell-extracellular matrix interactions.

Using siRNA techniques it was illustrated that knockdown of RAGE in A549 cells and human pulmonary fibroblasts resulted in increased migration as evaluated by chemotaxis migration and scratch wound healing assays [17]. Furthermore, both modified cell types exhibited increased proliferation. Of note, the effect of RAGE knockdown on migration was more pronounced in fibroblasts whilst conversely epithelial cells adopted greater proliferative capacity, suggesting that the specific role of RAGE may vary from one cell type to another.

In a developmental setting, it has been shown in rat lungs that levels of mRAGE and sRAGE at both the mRNA and protein level exhibit a gradual increase from foetal (E19) through to adulthood [24]. Given that the newborn rat lung is not fully alveolarised, this increase in RAGE levels may correspond to alveolarisation and expansion of the ATI cell population. Additionally, since sRAGE has been shown to inhibit RAGE dependent epithelial spreading in vitro [12], the deficiency of sRAGE at these early stages of development may serve to promote spreading of ATI cells during development of the alveolus.

Together, these findings indicate that RAGE may assist ATI cells to acquire a spread-out morphology and in doing so ensure effective gas exchange and alveolar stability. Given its apparently important role in modulating adhesion of alveolar epithelial cells to the basement membrane, a role for RAGE in pathologies such as cancer and fibrosis, in which these interactions are altered or impaired, appears likely.

\section{RAGE and Lung Cancer}

Recent evidence indicates that RAGE plays an important role in cancer. RAGE ligands, which include the S100/calgranulins and high-mobility group box 1 (HMGB1) protein, are expressed and secreted by cancer cells and cause cellular activation, resulting in enhanced expression of cytokines and growth factors, increased cell migration, and activation of the transcription factor, NF- $\kappa \mathrm{B}$ [25]. In tumours, because blockade of RAGE reduces tumour cell growth and metastases, it might be expected that the most invasive tumours would have the highest levels of RAGE. While this appears to be the case for prostate, colon, and gastric tumours, curiously, lung cancers, among the most invasive of tumours, are reported to express low levels of RAGE [26, 27]. Reduced levels of RAGE have been observed in non-small cell lung carcinoma (NSCLC) compared with the normal lung [21,28-33]. Only one publication reported abundant RAGE expression in lung tumour specimens by microarray [34]. Down-regulation of RAGE, on the other hand, correlated well with higher tumour stages [21]. Moreover, overexpression of full-length human RAGE in H358 lung cancer cells resulted in reduced tumour growth compared to that in dominant-negative RAGE expressing cells in vivo [35]. Recently, it was found that esRAGE, the splice variant that is secreted and acts as an antagonist, is also down-regulated in NSCLC [36].

Amphoterin (HMGB1) is a high mobility group I nonhistone DNA-binding protein that can be secreted into the extracellular space during certain stages of development or in necrotic cells, where it triggers inflammation [37]. Although it is unclear to what extent amphoterin is located in the extracellular space of tumour cells, the interaction of amphoterin with RAGE has been suggested to contribute to tumour growth and especially, to invasive migration and metastasis [26]. Blockade of the amphoterin-RAGE interaction decreased matrix metalloproteinase (MMP) activity and inhibited tumour growth and metastases [38]. MMPs which are able to degrade almost all extracellular matrix components have been shown to associate with increased metastatic potential in many cancer types [39]. Bartling et al. [21] demonstrated that overexpression of RAGE in lung cancer cells without additional application of amphoterin does not mediate an increased tumour growth in athymic mice. Overexpression of full-length human RAGE in lung cancer cells even showed a diminished in vitro proliferation in monolayer cell cultures compared with cells expressing the cytoplasmic deletion mutant of RAGE ( $\Delta$ cytoRAGE) or mock transfected cells.

Other RAGE-ligands are also suggested to be expressed in lung cancer. S100P overexpression in NSCLC associated with poor survival was reported in two studies $[40,41]$. Furthermore, overexpression of S100P but not S100A2 in the HTB-58 NSCLC cell line increased its transendothelial migration [41]. S100A4 and S100A6 were also found to be up-regulated in lung tumours [34, 42]. Reduced E-cadherin expression combined with higher S100A4 expression was associated with poor prognosis due to increased metastasis in pulmonary adenocarcinoma [43].

RAGE ligands are widely overexpressed in lung cancer, while the receptor itself seems to be down-regulated or cleaved proteolytically. The broad range of ligands with which RAGE interacts and the multiple alternative mechanisms of action of these ligands make it difficult to determine the specific mechanisms involved in particular functions. 
It appears that interference with RAGE ligands will be of therapeutic benefit in lung cancer, but further study is needed to fully understand the role of RAGE and its ligands in this aggressive cancer pathology.

\section{RAGE Alteration during Exposure to Cigarette Smoke and Radon}

The two leading risk factors for lung cancer are cigarette smoke and radon exposure [44]. The group of Jian Tong extensively studied alterations of RAGE and its ligands by proteomics, after exposure of rats to these noxious agents [45-47]. They found that RAGE and S100A6 were upregulated in a dose-dependant manner when rats were exposed to radon for cumulative doses up to 400 working level months (WLM) [45]. A similar effect was observed when rats were exposed to cigarette smoke twice daily for up to 4 months [46]. When combining the two insults, that is, exposing the rat to cigarette smoke (75 days) plus radon (200 WLM), similar alterations in protein expression resulted [47]. By immunohistochemistry the RAGE signal was predominantly observed at the alveolar interstitium and epithelial cells. Reynolds et al. [48] demonstrated that RAGE, S100A12, and amphoterin were up-regulated in a rat (R3/1) and human (A549) alveolar epithelial cells and macrophages (RAW 264.7) following exposure to cigarette smoke extract (CSE). They further confirmed elevated RAGE levels in the lungs of mice exposed to cigarette smoke for 6 months. RAGE level was influenced by differential expression of transcription factors such as TTF-1 and Egr-1 and that activation of RAGE and Egr-1 by cigarette smoke synergistically elaborated both RAGE and its ligands to maintain RAGE signalling [48]. The same group also reported that Ras was induced in R3/1 cells after exposure to CSE, resulting in up-regulation of NF- $\kappa \mathrm{B}$, leading to increased secretion of proinflammatory cytokines such as TNF $\alpha$, IL- $1 \beta$, and IL-8 [49]. When cells were treated with siRNA for RAGE, Ras and NF- $\kappa$ B activation was decreased [50]. In human lungs with lesions associated with smoking, immunohistochemical studies have shown that bronchiolar epithelia, areas of alveolar bronchialisation, reactive pneumocytes, and alveolar macrophages all exhibit widespread RAGE reactivity [13]. S100A12 was found to be expressed in polymorphonuclear granulocytes and in extracellular fluid, whilst low reactivity was seen in bronchiolar epithelia and a number of macrophages. Moreover, both the number of carboxymethyl-lysine positive cells and intensity of expression were measurably enhanced in epithelial and inflammatory cells of the lungs of smokers.

\section{RAGE and Pulmonary Fibrosis}

Similar to lung cancer, fibrotic processes are disorders in which cell attachment and cell communication are critical events. RAGE has been implicated in the fibrotic process in a number of tissues, including the peritoneum, kidney, and liver [51-53], where it has been shown to promote fibrosis. In the lung, evidence continues to accumulate suggesting an important role for RAGE in pulmonary fibrosis, although data is conflicting if RAGE has a protective function or is indeed a culprit.

In animal models of pulmonary fibrosis, both membrane RAGE and sRAGE protein levels have been shown to be reduced following treatment with bleomycin, asbestos, or silica [54-56]. In the case of bleomycin injury, loss of mRAGE was seen within 24 hours [55] and a reduction in sRAGE observed as early as day 2 [54], with levels of both remaining reduced at day $7[54,55]$. The deleterious effects of asbestos on expression of both mRAGE and sRAGE were evident within 24 hours and maintained to day 14 following treatment [55]. In common with asbestos, silica was found to induce a loss of RAGE which was apparent in samples isolated two weeks after treatment [56]. A similar decrease in RAGE has also been illustrated in ATI cells isolated from rat lung slices treated with $\mathrm{CdCl}_{2}$ and TGF- $\beta 1$ [57]. Investigations by Englert et al. [55] have shown that RAGE-deficient (RAGE -/-) mice spontaneously develop fibrosis-like alterations in lungs, exhibiting enhanced levels of collagen I and increased hydroxyproline content. Furthermore, following treatment with asbestos, these mice develop a fibrosis which is more severe compared to control mice.

Similar findings have been illustrated in lung homogenates and broncho-alveolar lavage fluid (BALF) from patients suffering form idiopathic pulmonary fibrosis (IPF). Both Englert et al. [55] and Queisser et al. [17] report that RAGE protein levels in lung homogenates were reduced in comparison to healthy donor samples. A lower concentration of sRAGE was also found in BALF of IPF patients [58]. Moreover, the RAGE gene has been shown to be significantly down-regulated in IPF lungs $[55,59,60]$. Together, these findings suggest that loss of RAGE may serve to promote fibrosis in the lung or that RAGE down-regulation is a result of this pathology.

In contrast, He and colleagues [61] report that RAGE $-/$ mice were resistant to bleomycin induced lung injury with enhanced survival rates and lower fibrotic scores. They showed that protein levels of the pro-fibrotic cytokines TGF- $\beta 1$ and PDGF in BALF failed to increase in RAGE $-/-$ mice following bleomycin treatment, in contrast to wildtype mice. Additionally, HMGB1 increased in mice treated with bleomycin. Coupled to this, ATII cells cultured in the presence of HMGB1 were found to undergo epithelialmesenchymal transition (EMT). In cells isolated from RAGE - /- mice, HMGB1 failed to induce EMT suggesting a potential role for RAGE signalling in HMGB1-induced EMT. These findings are in accordance with the traditionally held view of RAGE as being profibrotic [51-53] and that the RAGE expression is controlled by cytokines [62].

Findings by Morbini et al. [13] lend further evidence to a role for RAGE in promoting fibrosis. In immunohistochemical studies of lung samples from IPF patients, overexpression of RAGE was found in reactive pneumocytes, bronchiolar metaplastic epithelium, and endothelium. Interestingly, overexpression was most apparent in fibroblastic foci. Additionally, in a recent study by Chen et al. [63] it was shown that AGE levels in rat lungs were increased significantly following bleomycin instillation. Interestingly, 
when formation of AGEs was blocked through treatment with aminoguanidine, bleomycin-induced fibrosis was attenuated. It is unclear, however, as to what extent this involves its receptor, RAGE.

In those suffering from cystic fibrosis (CF), injury to the lung as a consequence of sustained inflammation is the most prevalent cause of morbidity and mortality [64]. The S100 family of calcium binding proteins has been implicated in this process. It has been suggested that these proteins mediate their proinflammatory effects in CF via RAGE. Studies by Foell et al. [65] have shown that S100A12 is locally expressed by infiltrating neutrophils in the lungs of CF patients. Furthermore, it has been illustrated that levels of S100A12 in the sputum of CF patients are extremely high $[65,66]$. During acute infectious exacerbations, serum levels were found to be increased in comparison to controls [65]. Interestingly, intravenous antibiotic treatment successfully reduced S100A12 levels. In addition, RAGE expression in CF neutrophils was significantly enhanced along with a reduction in levels of sRAGE [66]. Together, this points towards an important role for RAGE in neutrophil associated airway inflammation in CF.

Currently, it is unclear as to the exact role of RAGE in fibrosis of the lung. A number of studies undertaken using animal models of fibrosis have produced conflicting results. These findings highlight the acknowledged limitations of such models [67] and consequently limit the extent to which inference can be drawn from them. Furthermore, whilst a number of studies report a loss of RAGE under experimental conditions of fibrosis, it is unclear as to whether this is due to a down-regulation of RAGE itself or simply a loss of alveolar type I epithelial cells, the primary expresser of RAGE.

\section{RAGE and Acute Lung Injury and Acute Respiratory Distress Syndrome}

Acute lung injury (ALI) and acute respiratory distress syndrome (ARDS), a more severe manifestation, are characterised by deterioration of the alveolar-capillary barrier together with impaired alveolar fluid clearance (AFC) [68].

Core to this process is the damage of ATI cells, which under physiological conditions help maintain the integrity of the alveolar-capillary barrier in addition to transporting sodium and thus, ensuring an intact AFC. Given this, RAGE, which is expressed primarily in ATI cells, has been suggested as a biomarker for ALI and ARDS $[54,69]$.

Several different animal models of ALI resulted in increased RAGE levels in the BALF [69-74]. However, the level of response varied depending on the experimental model used. Su et al. [72] reported that RAGE levels in BALF were elevated 58-, 22-, and 13-fold after intratracheal instillation of hydrochloric acid, lipopolysaccharide (LPS), and Escherichia coli in mice. The same study also showed an increase in BALF RAGE after hyperoxia $\left(95 \% \mathrm{O}_{2}, 96 \mathrm{~h}\right)$. Hyperoxia $\left(75 \% \mathrm{O}_{2}, 96 \mathrm{~h}\right)$ was recently reported to upregulate both membrane RAGE and sRAGE protein in mice as well as RAGE mRNA in alveolar epithelial cells in primary culture under hyperoxic conditions [73]. RAGE knock-out mice, however, were protected from hyperoxiainduced mortality, had less protein in BALF and diminished lung fluid, fewer total BALF cells and reduced secretion of proinflammatory cytokines [73]. Parmley and colleagues [74] demonstrated that lung injury induced by cytokine (IL$1 \alpha$ and IFN $-\gamma$ ) instillation was associated with increased inflammation, tissue damage, and elevation of RAGE, ICAM-1, VCAM-1, and LDH levels (in BALF). Antagonists of $\alpha 4 / \beta 1$ and $\alpha \mathrm{L} / \beta 2$ integrins suppressed adhesion of MNP and modulated release of RAGE and LDH [74].

In contrast to these direct models of lung injury, ALI induced indirectly using either MHC I antibodies (i.v.) or thiourea (i.p.) failed to alter RAGE levels in the BALF [72]. Uchida et al. [69] had previously demonstrated that RAGE levels in the BALF and serum varied with the severity of lung injury following i.t. instillation of $\mathrm{HCl}$ into rats, whereas RAGE was not detected in serum from LPS-instilled animals. This suggests that different pathways might be involved in RAGE release into the BALF and serum, depending on the nature of the insult. When studying LPS-induced lung injury in mice, Zhang et al. [71] confirmed that sRAGE levels in the BALF are increased 24 hours after LPS instillation (but not after $6 \mathrm{~h}$ ). They also reported that sRAGE injected i.p. 1 hour after LPS instillation was able to attenuate BALF total cell count, neutrophils, lung permeability index, and NF- $\kappa$ B activity. Moreover, sRAGE treatment significantly attenuated up-regulation of several (but not all) proinflammatory cytokines in BALF, while with the exception of MIP- $1 \beta$, no significant difference in cytokine serum levels between the LPS and the LPS plus sRAGE groups was observed [71]. These results suggest that sRAGE blockade of HMGB-1induced increase in proinflammatory cytokines is restricted to the lung.

When comparing RAGE levels in pulmonary oedema fluid and plasma from patients with ALI/ARDS with a group of patients with hydrostatic pulmonary oedema, the RAGE levels in ALI/ARDS were significantly higher than those from patients with hydrostatic pulmonary oedema or control [69]. Furthermore, RAGE levels in the alveolar oedema fluid were significantly higher than plasma in patients with pulmonary oedema. This finding suggested that the source of RAGE in these samples was predominantly from the lungs rather than from the circulation. Additionally, poorer clinical outcomes in patients with ALI have been shown to be strongly correlated with higher baseline plasma sRAGE levels [75], whilst both airspace and perfusate sRAGE levels appeared to be negatively correlated with AFC [76, 77]. In support of this, the RAGE ligand S100A12 was enhanced in pulmonary tissues of ARDS patients, coupled with an increased concentration of S100A12 in BALF [78], whilst HMGB1, another RAGE ligand has been shown to induce neutrophil accumulation, lung oedema, and release of cytokines $[79,80]$. Given that RAGE is the primary receptor through which these ligands act, blockade of this interaction would appear to be of benefit in assisting in the resolution of lung injury.

From these findings it can be speculated that RAGE is released from ATI cells during ALI/ARDS either via apoptotic events or controlled shedding, for example, via MMPs from 
the epithelium of infiltrated leukocytes [81]. RAGE can then potentially participate in a negative feedback after excessive inflammation by acting as a decoy receptor for, for example, HMGB1, which is know to be up-regulated in response to LPS and causes an inflammatory response manifested by increasing production of cytokines [82].

\section{RAGE and Other Pulmonary Disorders}

Sarcoidosis, a disease state characterised by noncaseating granulomae, has been illustrated to exhibit expression of RAGE together with its ligands $[13,83]$. Furthermore, it was shown that a specific polymorphism, which is associated with greater transcriptional activity of RAGE, is more prevalent in sarcoidosis patients compared with healthy subjects [83].

In immunohistochemical studies, overexpression of RAGE was most prominent in epithelia associated with inflammatory cell aggregates in organising pneumonia [13]. In addition, in a recent study RAGE deficiency was shown to protect against pneumococcal pneumonia in a murine model [84]. RAGE -/- mice intranasally inoculated with Streptococcus pneumoniae exhibited improved survival together with lower bacterial load in the lungs after 16 hours and reduced distribution of bacteria to the blood and spleen. Moreover, macrophages isolated from RAGE $-/-$ mice possessed an elevated killing capacity, suggesting a possible mechanism by which RAGE deficiency may serve to ameliorate the deleterious effects of $S$. pneumoniae. In line with the findings of Morbini et al. [13], expression of RAGE in lung tissue of mice treated with $S$. pneumoniae was found to be enhanced. Additionally, inflammation of the lung was reduced in mice lacking RAGE, whilst migration of neutrophils to the lungs was alleviated. RAGE $-/-$ mice also displayed reduced activation of coagulation, suggesting that RAGE potentially acts, at least in part, as a mediator of coagulation [85]. Similarly, in influenza A virus model of pneumonia, RAGE $(-/-)$ mice exhibited enhanced resistance to pneumonia as illustrated by increased survival and improved viral clearance. This was coupled with a superior cellular $\mathrm{T}$ cell response and neutrophil activation [86]. Implicit in the inflammatory response to infection is the careful balance between benefit and harm. Collectively, these results indicate that RAGE may perturb this balance giving rise to a sustained inflammatory response.

A study by Calfee et al. [87] of patients undergoing lung transplantation indicated that plasma sRAGE levels were associated with a more prolonged duration of mechanical ventilation and ICU length of stay. Moreover, when measured with 4 hours of allograft reperfusion, it proved a better prognostic marker for these short-term outcomes when compared to the clinical diagnosis of primary graft dysfunction. Sternberg and coworkers' [88] investigations lend further support to suggest an important role for RAGE signalling in lung injury following transplantation surgery. Through blockade of RAGE, they explored the functional relevance of RAGE signalling in animals subjected to pulmonary ischemia and reperfusion injury (IR). Of note, IR is

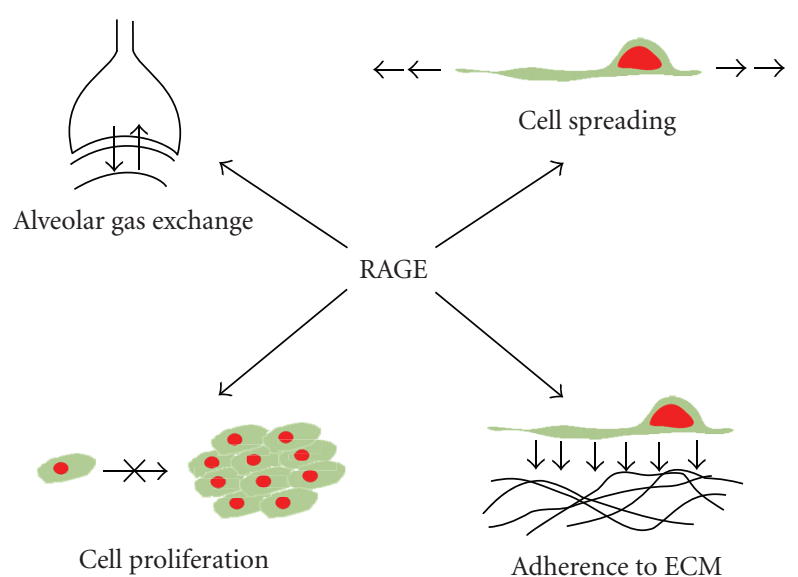

FIgURE 3: RAGE is central to many fundamental biological processes in the lung. Expression of RAGE has been shown to promote spreading of adherent cells on collagen IV and in doing so may ensure effective gas exchange. RAGE-expressing epithelial cells exhibit diminished proliferative capacity compared to nonexpressing cells. Cells overexpressing RAGE adhere much faster to collagen IV, and to a greater extent when compared to mock transfected cells suggesting an important role in cell-extracellular matrix interactions.

thought to be directly linked to primary graft dysfunction, one of the principal sources of morbidity following lung transplantation. They revealed that animals treated with sRAGE exhibited enhanced oxygenation and a reduction in capillary leakage, coupled with improved histological injury. These findings were further reinforced by that fact that RAGE $-/$ - mice also failed to develop pulmonary reperfusion injury. In addition, production of IL-8 and activation of NF- $\kappa$ B, both implicated in the pathogenesis of IR, failed to increase in contrast to controls. Whilst these results infer a role for RAGE in inflammatory signalling, surprisingly, RAGE at mRNA and protein levels were found to decrease following injury. Clearly, further investigations are required to fully elucidate the exact role of RAGE signalling in this pathology.

\section{Concluding Remarks}

Unlike in other tissues, RAGE is highly expressed in the lung under normal physiological conditions. Given this, it has been suggested that RAGE may exhibit properties restricted solely to the pulmonary environment. Indeed, studies have illustrated that RAGE possesses a number of important physiological roles in the lung including modulation of cell spreading, adhesion to ECM components, proliferation, and migration (Figure 3). Moreover, disturbance of this basal expression level appears to result in impaired functioning of RAGE, giving rise to pathological states including cancer and fibrosis. However, it remains unclear as to whether this is associated with down-regulation or up-regulation of expression at mRNA and protein levels with current studies reporting conflicting results. 
In addition, evidence continues to accumulate for the existence of numerous isoforms of RAGE. It is likely that many of these isoforms exhibit unique properties, with expression in some instances limited to specific cells or tissues. Notably, its soluble isoforms have been shown to be an important marker of injury to ATI cells. Furthermore, sRAGE is known to act as a decoy receptor binding ligands which otherwise would interact with full-length, membranebound RAGE. Clearly, developing a greater understanding of each isoform's expression, function, and interaction is essential in order to establish an accurate picture of the behaviour of RAGE in the lung.

Undoubtedly, RAGE and its isoforms play an essential role in the biology of the lung under both physiological and pathological conditions. However, it is vital that future studies address the relative contribution of both RAGE and its isoforms whilst continuing to ensure that those experimental models used reflect conditions in vivo.

\section{Acknowledgments}

Stephen T. Buckley is funded by an IRCSET Government of Ireland Postgraduate Scholarship in Science, Engineering and Technology. This work has been funded in part by a Strategic Research Cluster Grant (07/SRC/B1154) under the National Development Plan cofunded by EU Structural Funds and Science Foundation Ireland.

\section{References}

[1] M. Neeper, A. M. Schmidt, J. Brett, et al., "Cloning and expression of a cell surface receptor for advanced glycosylation end products of proteins," Journal of Biological Chemistry, vol. 267, no. 21, pp. 14998-15004, 1992.

[2] A. M. Schmidt, M. Vianna, M. Gerlach, et al., "Isolation and characterization of two binding proteins for advanced glycosylation end products from bovine lung which are present on the endothelial cell surface," Journal of Biological Chemistry, vol. 267, no. 21, pp. 14987-14997, 1992.

[3] A. M. Schmidt, S. D. Yan, S. F. Yan, and D. M. Stern, "The multiligand receptor RAGE as a progression factor amplifying immune and inflammatory responses," Journal of Clinical Investigation, vol. 108, no. 7, pp. 949-955, 2001.

[4] T. Chavakis, A. Bierhaus, N. Al-Fakhri, et al., "The pattern recognition receptor (RAGE) is a counterreceptor for leukocyte integrins: a novel pathway for inflammatory cell recruitment," Journal of Experimental Medicine, vol. 198, no. 10, pp. 1507-1515, 2003.

[5] A. M. Schmidt, S. D. Yan, J.-L. Wautier, and D. Stern, "Activation of receptor for advanced glycation end products: a mechanism for chronic vascular dysfunction in diabetic vasculopathy and atherosclerosis," Circulation Research, vol. 84, no. 5, pp. 489-497, 1999.

[6] H. Yonekura, Y. Yamamoto, S. Sakurai, et al., "Novel splice variants of the receptor for advanced glycation end-products expressed in human vascular endothelial cells and pericytes, and their putative roles in diabetes-induced vascular injury," Biochemical Journal, vol. 370, no. 3, pp. 1097-1109, 2003.

[7] L. E. Hanford, J. J. Enghild, Z. Valnickova, et al., "Purification and characterization of mouse soluble receptor for advanced glycation end products (sRAGE)," Journal of Biological Chemistry, vol. 279, no. 48, pp. 50019-50024, 2004.
[8] A. Raucci, S. Cugusi, A. Antonelli, et al., "A soluble form of the receptor for advanced glycation endproducts (RAGE) is produced by proteolytic cleavage of the membrane-bound form by the sheddase a disintegrin and metalloprotease 10 (ADAM10)," The FASEB Journal, vol. 22, no. 10, pp. 37163727, 2008.

[9] J. V. Gefter, A. L. Shaufl, M. P. Fink, and R. L. Delude, "Comparison of distinct protein isoforms of the receptor for advanced glycation end-products expressed in murine tissues and cell lines," Cell and Tissue Research, vol. 337, no. 1, pp. 79$89,2009$.

[10] J. Brett, A. M. Schmidt, S. D. Yan, et al., "Survey of the distribution of a newly characterized receptor for advanced glycation end products in tissues," American Journal of Pathology, vol. 143, no. 6, pp. 1699-1712, 1993.

[11] T. Barrett, D. B. Troup, S. E. Wilhite, et al., "NCBI GEO: mining tens of millions of expression profiles-database and tools update," Nucleic Acids Research, vol. 35, database issue, pp. D760-D765, 2007.

[12] N. Demling, C. Ehrhardt, M. Kasper, M. Laue, L. Knels, and E. P. Rieber, "Promotion of cell adherence and spreading: a novel function of RAGE, the highly selective differentiation marker of human alveolar epithelial type I cells," Cell and Tissue Research, vol. 323, no. 3, pp. 475-488, 2006.

[13] P. Morbini, C. Villa, I. Campo, M. Zorzetto, S. Inghilleri, and M. Luisetti, "The receptor for advanced glycation end products and its ligands: a new inflammatory pathway in lung disease?" Modern Pathology, vol. 19, no. 11, pp. 1437-1445, 2006.

[14] H. Fehrenbach, M. Kasper, T. Tschernig, M. S. Shearman, D. Schuh, and M. Müller, "Receptor for advanced glycation endproducts (RAGE) exhibits highly differential cellular and subcellular localisation in rat and human lung," Cellular and Molecular Biology, vol. 44, no. 7, pp. 1147-1157, 1998.

[15] F. Katsuoka, Y. Kawakami, T. Arai, et al., "Type II alveolar epithelial cells in lung express receptor for advanced glycation end products (RAGE) gene," Biochemical and Biophysical Research Communications, vol. 238, no. 2, pp. 512-516, 1997.

[16] N. Nakano, K. Fukuhara-Takaki, T. Jono, et al., "Association of advanced glycation end products with A549 cells, a human pulmonary epithelial cell line, is mediated by a receptor distinct from the scavenger receptor family and RAGE," Journal of Biochemistry, vol. 139, no. 5, pp. 821-829, 2006.

[17] M. A. Queisser, F. M. Kouri, M. Königshoff, et al., "Loss of RAGE in pulmonary fibrosis: molecular relations to functional changes in pulmonary cell types," American Journal of Respiratory Cell and Molecular Biology, vol. 39, no. 3, pp. 337-345, 2008.

[18] K. Dahlin, E. M. Mager, L. Allen, et al., "Identification of genes differentially expressed in rat alveolar type I cells," American Journal of Respiratory Cell and Molecular Biology, vol. 31, no. 3, pp. 309-316, 2004.

[19] R. Koslowski, K. Barth, A. Augstein, et al., "A new rat type I-like alveolar epithelial cell line R3/1: bleomycin effects on caveolin expression," Histochemistry and Cell Biology, vol. 121, no. 6, pp. 509-519, 2004.

[20] M. Shirasawa, N. Fujiwara, S. Hirabayashi, et al., "Receptor for advanced glycation end-products is a marker of type I lung alveolar cells," Genes to Cells, vol. 9, no. 2, pp. 165-174, 2004.

[21] B. Bartling, H.-S. Hofmann, B. Weigle, R.-E. Silber, and A. Simm, "Down-regulation of the receptor for advanced glycation end-products (RAGE) supports non-small cell lung carcinoma," Carcinogenesis, vol. 26, no. 2, pp. 293-301, 2005. 
[22] J. M. Englert, L. J. Sparvero, A. A. Amoscato, M. T. Lotze, and T. D. Oury, "RAGE and the lung extracellular matrix: a novel protective function," American Journal of Respiratory and Critical Care Medicine, vol. 179, no. 1, A4990, 2009.

[23] O. Hori, J. Brett, T. Slattery, et al., "The receptor for advanced glycation end products (RAGE) is a cellular binding site for amphoterin. Mediation of neurite outgrowth and co-expression of RAGE and amphoterin in the developing nervous system," Journal of Biological Chemistry, vol. 270, no. 43, pp. 25752-25761, 1995.

[24] P.-P. Lizotte, L. E. Hanford, J. J. Enghild, E. Nozik-Grayck, B.-L. Giles, and T. D. Oury, "Developmental expression of the receptor for advanced glycation end-products (RAGE) and its response to hyperoxia in the neonatal rat lung," BMC Developmental Biology, vol. 7, article 15, pp. 1-9, 2007.

[25] L. J. Sparvero, D. Asafu-Adjei, R. Kang, et al., "RAGE (Receptor for advanced glycation endproducts), RAGE ligands, and their role in cancer and inflammation," Journal of Translational Medicine, vol. 7, article 17, pp. 1-21, 2009.

[26] C. D. Logsdon, M. K. Fuentes, E. H. Huang, and T. Arumugam, "RAGE and RAGE ligands in cancer," Current Molecular Medicine, vol. 7, no. 8, pp. 777-789, 2007.

[27] W. A. Franklin, "RAGE in lung tumors," American Journal of Respiratory and Critical Care Medicine, vol. 175, no. 2, pp. 106107, 2007.

[28] P. Schraml, R. Shipman, M. Colombi, and C. U. Ludwig, "Identification of genes differentially expressed in normal lung and non-small cell lung carcinoma tissue," Cancer Research, vol. 54, no. 19, pp. 5236-5240, 1994.

[29] P. Schraml, I. Bendik, and C. U. Ludwig, "Differential messenger RNA and protein expression of the receptor for advanced glycosylated end products in normal lung and nonsmall cell lung carcinoma," Cancer Research, vol. 57, no. 17, pp. 3669-3671, 1997.

[30] S. Schenk, P. Schraml, I. Bendik, and C. U. Ludwig, "A novel polymorphism in the promoter of the RAGE gene is associated with non-small cell lung cancer," Lung Cancer, vol. 32, no. 1, pp. 7-12, 2001.

[31] H.-S. Hofmann, G. Hansen, S. Burdach, B. Bartling, R.E. Silber, and A. Simm, "Discrimination of human lung neoplasm from normal lung by two target genes," American Journal of Respiratory and Critical Care Medicine, vol. 170, no. 5, pp. 516-519, 2004.

[32] D. Stav, I. Bar, and J. Sandbank, "Usefulness of CDK5RAP3, CCNB2, and RAGE genes for the diagnosis of lung adenocarcinoma," International Journal of Biological Markers, vol. 22, no. 2, pp. 108-113, 2007.

[33] J.-H. Rho, M. H. A. Roehrl, and J. Y. Wang, "Glycoproteomic analysis of human lung adenocarcinomas using glycoarrays and tandem mass spectrometry: differential expression and glycosylation patterns of vimentin and fetuin A isoforms," Protein Journal, vol. 28, no. 3-4, pp. 148-160, 2009.

[34] H.-L. Hsieh, B. W. Schäfer, N. Sasaki, and C. W. Heizmann, "Expression analysis of S100 proteins and RAGE in human tumors using tissue microarrays," Biochemical and Biophysical Research Communications, vol. 307, no. 2, pp. 375-381, 2003.

[35] B. Bartling, N. Demling, R.-E. Silber, and A. Simm, "Proliferative stimulus of lung fibroblasts on lung cancer cells is impaired by the receptor for advanced glycation endproducts," American Journal of Respiratory Cell and Molecular Biology, vol. 34, no. 1, pp. 83-91, 2006.

[36] S. Kobayashi, H. Kubo, T. Suzuki, et al., "Endogenous secretory receptor for advanced glycation end products in nonsmall cell lung carcinoma," American Journal of Respiratory and Critical Care Medicine, vol. 175, no. 2, pp. 184-189, 2007.
[37] L. Campana, L. Bosurgi, and P. Rovere-Querini, "HMGB1: a two-headed signal regulating tumor progression and immunity," Current Opinion in Immunology, vol. 20, no. 5, pp. 518$523,2008$.

[38] A. Taguchi, D. C. Blood, G. del Toro, et al., "Blockade of RAGE-amphoterin signalling suppresses tumour growth and metastases," Nature, vol. 405, no. 6784, pp. 354-360, 2000.

[39] K. Nabeshima, T. Inoue, Y. Shimao, and T. Sameshima, "Matrix metalloproteinases in tumor invasion: role for cell migration," Pathology International, vol. 52, no. 4, pp. 255264, 2002.

[40] D. G. Beer, S. L. R. Kardia, C.-C. Huang, et al., "Geneexpression profiles predict survival of patients with lung adenocarcinoma," Nature Medicine, vol. 8, no. 8, pp. 816-824, 2002.

[41] S. Diederichs, E. Bulk, B. Steffen, et al., "S100 family members and trypsinogens are predictors of distant metastasis and survival in early-stage non-small cell lung cancer," Cancer Research, vol. 64, no. 16, pp. 5564-5569, 2004.

[42] K. Kimura, Y. Endo, Y. Yonemura, et al., "Clinical significance of S100A4 and E-cadherin-related adhesion molecules in nonsmall cell lung cancer," International Journal of Oncology, vol. 16, no. 6, pp. 1125-1131, 2000.

[43] N. Miyazaki, Y. Abe, Y. Oida, et al., "Poor outcome of patients with pulmonary adenocarcinoma showing decreased E-cadherin combined with increased S100A4 expression," International Journal of Oncology, vol. 28, no. 6, pp. 13691374, 2006.

[44] I. Brüske-Hohlfeld, "Environmental and occupational risk factors for lung cancer," Methods in Molecular Biology, vol. 472, pp. 3-23, 2009.

[45] N.-Y. Xu, S.-P. Zhang, J.-H. Nie, J.-X. Li, and J. Tong, "Radoninduced proteomic profile of lung tissue in rats," Journal of Toxicology and Environmental Health, Part A, vol. 71, no. 6, pp. 361-366, 2008.

[46] S. Zhang, N. Xu, J. Nie, L. Dong, J. Li, and J. Tong, "Proteomic alteration in lung tissue of rats exposed to cigarette smoke," Toxicology Letters, vol. 178, no. 3, pp. 191-196, 2008.

[47] N. Y. Xu, S. P. Zhang, L. Dong, J. H. Nie, and J. Tong, "Proteomic analysis of lung tissue of rats exposed to cigarette smoke and radon," Journal of Toxicology and Environmental Health, Part A, vol. 72, no. 11, pp. 752-758, 2009.

[48] P. R. Reynolds, S. D. Kasteler, M. G. Cosio, A. Sturrock, T. Huecksteadt, and J. R. Hoidal, "RAGE: developmental expression and positive feedback regulation by Egr-1 during cigarette smoke exposure in pulmonary epithelial cells," American Journal of Physiology, vol. 294, no. 6, pp. L1094L1101, 2008.

[49] S. D. Kasteler, P. R. Reynolds, and J. R. Hoidal, "Downstream effects of receptors for advanced glycation end-products (RAGE) in pulmonary epithelial cells exposed to cigarette smoke," American Journal of Respiratory and Critical Care Medicine, vol. 177, no. 1, A333, 2008.

[50] P. R. Reynolds, R. E. Schmitt, S. D. Kasteler, and J. R. Hoidal, "The receptor for advanced glycation end products (RAGE) activates Tas and NF- $\kappa$ B in pulmonary epithelial cells exposed to cigarette smoke," American Journal of Respiratory and Critical Care Medicine, vol. 179, no. 1, A4185, 2009.

[51] A. S. De Vriese, R. G. Tilton, S. Mortier, and N. H. Lameire, "Myofibroblast transdifferentiation of mesothelial cells is mediated by RAGE and contributes to peritoneal fibrosis in uraemia," Nephrology Dialysis Transplantation, vol. 21, no. 9, pp. 2549-2555, 2006. 
[52] J. H. Li, W. Wang, X. R. Huang, et al., "Advanced glycation end products induce tubular epithelial-myofibroblast transition through the RAGE-ERK1/2 MAP kinase signaling pathway," American Journal of Pathology, vol. 164, no. 4, pp. 1389-1397, 2004.

[53] J.-R. Xia, N.-F. Liu, and N.-X. Zhu, "Specific siRNA targeting the receptor for advanced glycation end products inhibits experimental hepatic fibrosis in rats," International Journal of Molecular Sciences, vol. 9, no. 4, pp. 638-661, 2008.

[54] L. E. Hanford, C. L. Fattman, L. M. Schaefer, J. J. Enghild, Z. Valnickova, and T. D. Oury, "Regulation of receptor for advanced glycation end products during bleomycin-induced lung injury," American Journal of Respiratory Cell and Molecular Biology, vol. 29, no. 3, supplement, pp. S77-S81, 2003.

[55] J. M. Englert, L. E. Hanford, N. Kaminski, et al., "A role for the receptor for advanced glycation end products in idiopathic pulmonary fibrosis," American Journal of Pathology, vol. 172, no. 3, pp. 583-591, 2008.

[56] L. Ramsgaard, J. M. Englert, C. L. Tobolewski, and T. D. Oury, "The role of RAGE in pulmonary silicosis," American Journal of Respiratory and Critical Care Medicine, vol. 177, no. 1, A740, 2008.

[57] M. Kasper, D. Seidel, L. Knels, et al., "Early signs of lung fibrosis after in vitro treatment of rat lung slices with $\mathrm{CdCl} 2$ and TGF- $\beta 1$," Histochemistry and Cell Biology, vol. 121, no. 2, pp. 131-140, 2004.

[58] E. Bargagli, F. Penza, N. Bianchi, et al., "Controversial role of RAGE in the pathogenesis of idiopathic pulmonary fibrosis," Respiratory Physiology and Neurobiology, vol. 165, no. 2-3, pp. 119-120, 2009.

[59] M. Selman, G. Carrillo, A. Estrada, et al., "Accelerated variant of idiopathic pulmonary fibrosis: clinical behavior and gene expression pattern," PLoS One, vol. 2, no. 5, article e482, 2007.

[60] I. O. Rosas, T. J. Richards, K. Konishi, et al., "MMP1 and MMP7 as potential peripheral blood biomarkers in idiopathic pulmonary fibrosis," PLoS Medicine, vol. 5, no. 4, article e93, 2008.

[61] M. He, H. Kubo, K. Ishizawa, et al., "The role of the receptor for advanced glycation end-products in lung fibrosis," American Journal of Physiology, vol. 293, no. 6, pp. L1427L1436, 2007.

[62] N. Tanaka, H. Yonekura, S.-I. Yamagishi, H. Fujimori, Y. Yamamoto, and H. Yamamoto, "The receptor for advanced glycation end products is induced by the glycation products themselves and tumor necrosis factor- $\alpha$ through nuclear factor- $\kappa \mathrm{B}$, and by $17 \beta$-estradiol through sp- 1 in human vascular endothelial cells," Journal of Biological Chemistry, vol. 275, no. 33, pp. 25781-25790, 2000.

[63] L. Chen, T. Wang, X. Wang, et al., "Blockade of advanced glycation end product formation attenuates bleomycin-induced pulmonary fibrosis in rats," Respiratory Research, vol. 10, no. 1, p. 55, 2009.

[64] F. J. Accurso, "Introduction: the rational for early intervention in cystic fibrosis," Pediatric Pulmonology, vol. 24, no. 2, pp. 132-133, 1997.

[65] D. Foell, S. Seeliger, T. Vogl, et al., "Expression of S100A12 (EN-RAGE) in cystic fibrosis," Thorax, vol. 58, no. 7, pp. 613$617,2003$.

[66] M. Makam, D. Diaz, J. Laval, et al., "Activation of critical, host-induced, metabolic and stress pathways marks neutrophil entry into cystic fibrosis lungs," Proceedings of the National Academy of Sciences of the United States of America, vol. 106, no. 14 , pp. 5779-5783, 2009.
[67] B. B. Moore and C. M. Hogaboam, "Murine models of pulmonary fibrosis," American Journal of Physiology, vol. 294, no. 2, pp. L152-L160, 2008.

[68] R. Lucas, A. D. Verin, S. M. Black, and J. D. Catravas, "Regulators of endothelial and epithelial barrier integrity and function in acute lung injury," Biochemical Pharmacology, vol. 77, no. 12, pp. 1763-1772, 2009.

[69] T. Uchida, M. Shirasawa, L. B. Ware, et al., "Receptor for advanced glycation end-products is a marker of type I cell injury in acute lung injury," American Journal of Respiratory and Critical Care Medicine, vol. 173, no. 9, pp. 1008-1015, 2006.

[70] X. Su, J. W. Lee, Z. A. Matthay, et al., "Activation of the $\alpha 7 \mathrm{nAChR}$ reduces acid-induced acute lung injury in mice and rats," American Journal of Respiratory Cell and Molecular Biology, vol. 37, no. 2, pp. 186-192, 2007.

[71] H. Zhang, S. Tasaka, Y. Shiraishi, et al., "Role of soluble receptor for advanced glycation end products on endotoxininduced lung injury," American Journal of Respiratory and Critical Care Medicine, vol. 178, no. 4, pp. 356-362, 2008.

[72] X. Su, M. R. Looney, N. Gupta, and M. A. Matthay, "Receptor for advanced glycation end-products (RAGE) is an indicator of direct lung injury in models of experimental lung injury," American Journal of Physiology, vol. 297, no. 1, pp. L1-L5, 2009.

[73] P. R. Reynolds, R. E. Schmitt, S. D. Kasteler, et al., "Receptors for advanced glycation end-products (RAGE) targeting protect against hyperoxia-induced lung injury in mice," American Journal of Respiratory Cell and Molecular Biology. In press.

[74] L. A. Parmley, N. D. Elkins, M. A. Fini, Y.-E. Liu, J. E. Repine, and R. M. Wright, " $\alpha-4 / \beta-1$ and $\alpha-\mathrm{L} / \beta-2$ integrins mediate cytokine induced lung leukocyte-epithelial adhesion and injury," British Journal of Pharmacology, vol. 152, no. 6, pp. 915-929, 2007.

[75] C. S. Calfee, L. B. Ware, M. D. Eisner, et al., "Plasma receptor for advanced glycation end products and clinical outcomes in acute lung injury," Thorax, vol. 63, no. 12, pp. 1083-1089, 2008.

[76] J. A. Frank, R. Briot, J. W. Lee, A. Ishizaka, T. Uchida, and M. A. Matthay, "Physiological and biochemical markers of alveolar epithelial barrier dysfunction in perfused human lungs," American Journal of Physiology, vol. 293, no. 1, pp. L52L59, 2007.

[77] R. Briot, J. A. Frank, T. Uchida, J. W. Lee, C. S. Calfee, and M. A. Matthay, "Elevated levels of the receptor for advanced glycation end products, a marker of alveolar epithelial type I cell injury, predict impaired alveolar fluid clearance in isolated perfused human lungs," Chest, vol. 135, no. 2, pp. 269-275, 2009.

[78] H. Wittkowski, A. Sturrock, M. A. D. van Zoelen, et al., "Neutrophil-derived S100A12 in acute lung injury and respiratory distress syndrome," Critical Care Medicine, vol. 35, no. 5, pp. 1369-1375, 2007.

[79] E. Abraham, J. Arcaroli, A. Carmody, H. Wang, and K. J. Tracey, "Cutting edge: HMG-1 as a mediator of acute lung inflammation," Journal of Immunology, vol. 165, no. 6, pp. 2950-2954, 2000.

[80] H. Ueno, T. Matsuda, S. Hashimoto, et al., "Contributions of high mobility group box protein in experimental and clinical acute lung injury," American Journal of Respiratory and Critical Care Medicine, vol. 170, no. 12, pp. 1310-1316, 2004.

[81] N. Yamakawa, T. Uchida, M. A. Matthay, and K. Makita, "Expression of receptor for advanced glycation end-products 
(RAGE) in cultured alveolar epithelial cells," American Journal of Respiratory and Critical Care Medicine, vol. 177, no. 1, A723, 2008.

[82] E. Silva, J. Arcaroli, Q. He, et al., "HMGB1 and LPS induce distinct patterns of gene expression and activation in neutrophils from patients with sepsis-induced acute lung injury," Intensive Care Medicine, vol. 33, no. 10, pp. 1829-1839, 2007.

[83] I. Campo, P. Morbini, M. Zorzetto, et al., "Expression of receptor for advanced glycation end products in sarcoid granulomas," American Journal of Respiratory and Critical Care Medicine, vol. 175, no. 5, pp. 498-506, 2007.

[84] M. A. van Zoelen, M. Schouten, A. F. de Vos, et al., "The receptor for advanced glycation end products impairs host defense in pneumococcal pneumonia," Journal of Immunology, vol. 182, no. 7, pp. 4349-4356, 2009.

[85] M. A. D. van Zoelen, H. Yang, S. Florquin, et al., "Role of toll-like receptors 2 and 4 , and the receptor for advanced glycation end products in high-mobility group box 1-induced inflammation in vivo," Shock, vol. 31, no. 3, pp. 280-284, 2009.

[86] M. A. D. van Zoelen, K. F. van der Sluijs, A. Achouiti, et al., "Receptor for advanced glycation end products is detrimental during influenza A virus pneumonia," Virology, vol. 391, no. 2, pp. 265-273, 2009.

[87] C. S. Calfee, M. M. Budev, M. A. Matthay, et al., "Plasma receptor for advanced glycation end-products predicts duration of ICU stay and mechanical ventilation in patients after lung transplantation," Journal of Heart and Lung Transplantation, vol. 26, no. 7, pp. 675-680, 2007.

[88] D. I. Sternberg, R. Gowda, D. Mehra, et al., "Blockade of receptor for advanced glycation end product attenuates pulmonary reperfusion injury in mice," Journal of Thoracic and Cardiovascular Surgery, vol. 136, no. 6, pp. 1576-1585, 2008. 

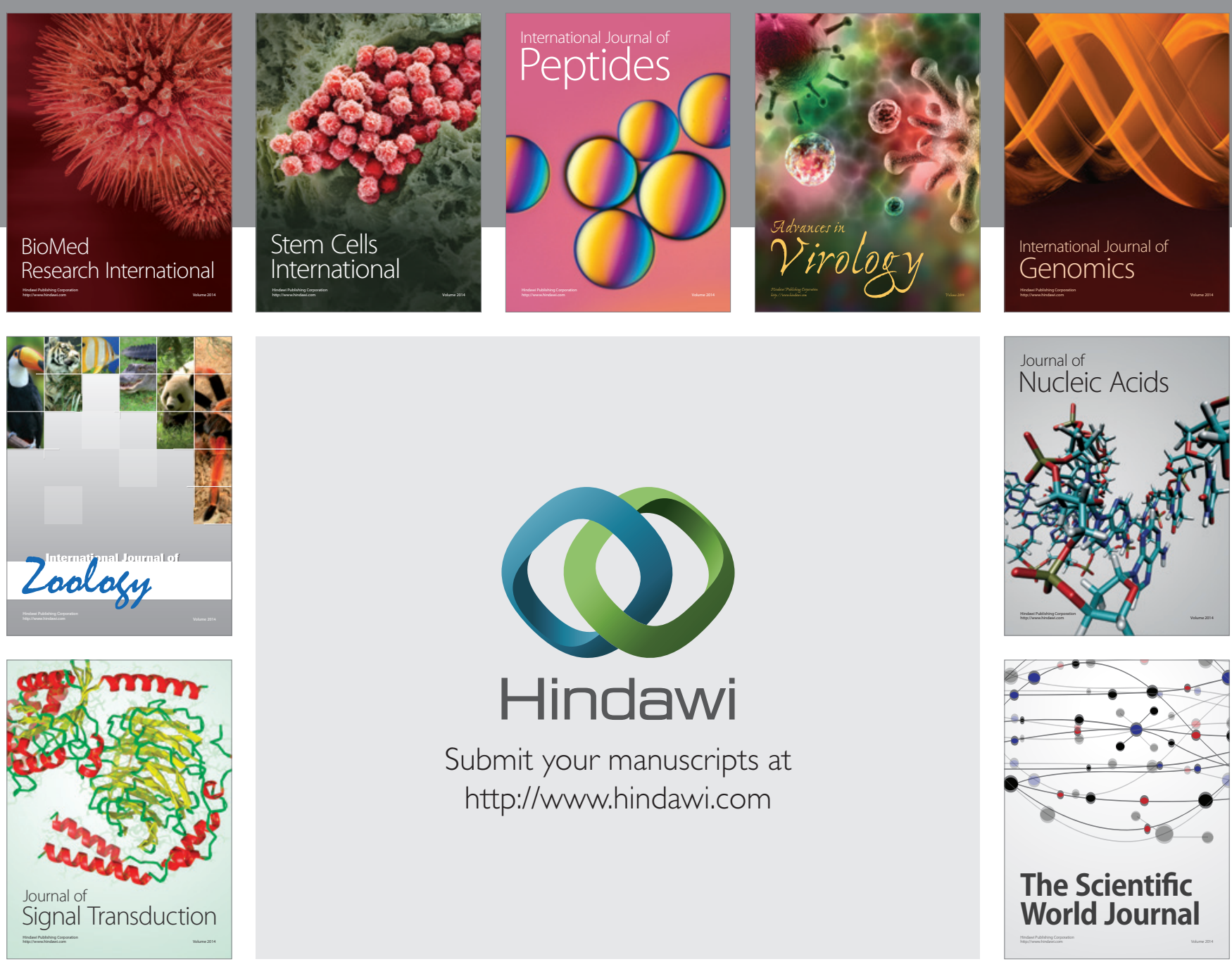

Submit your manuscripts at

http://www.hindawi.com
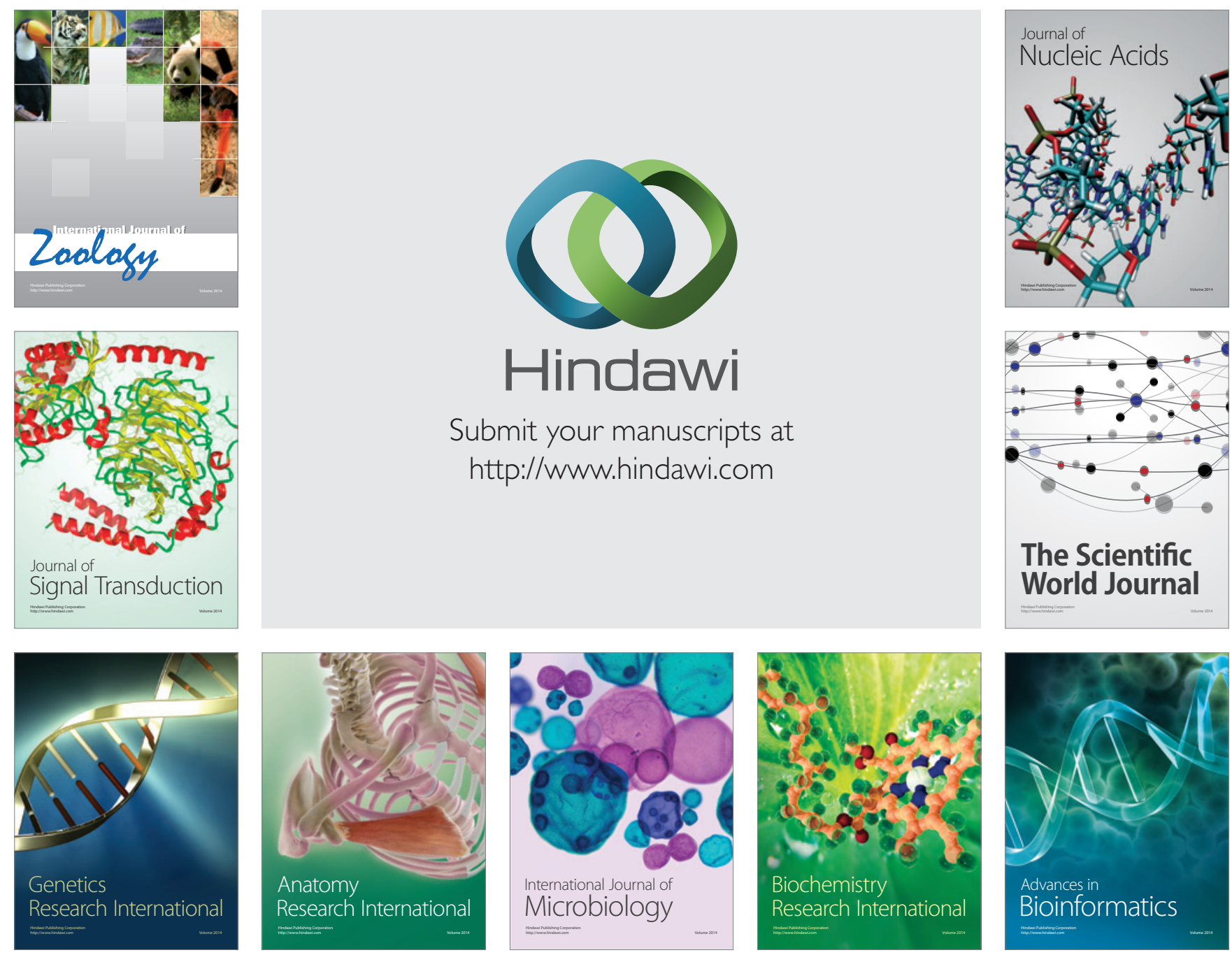

The Scientific World Journal
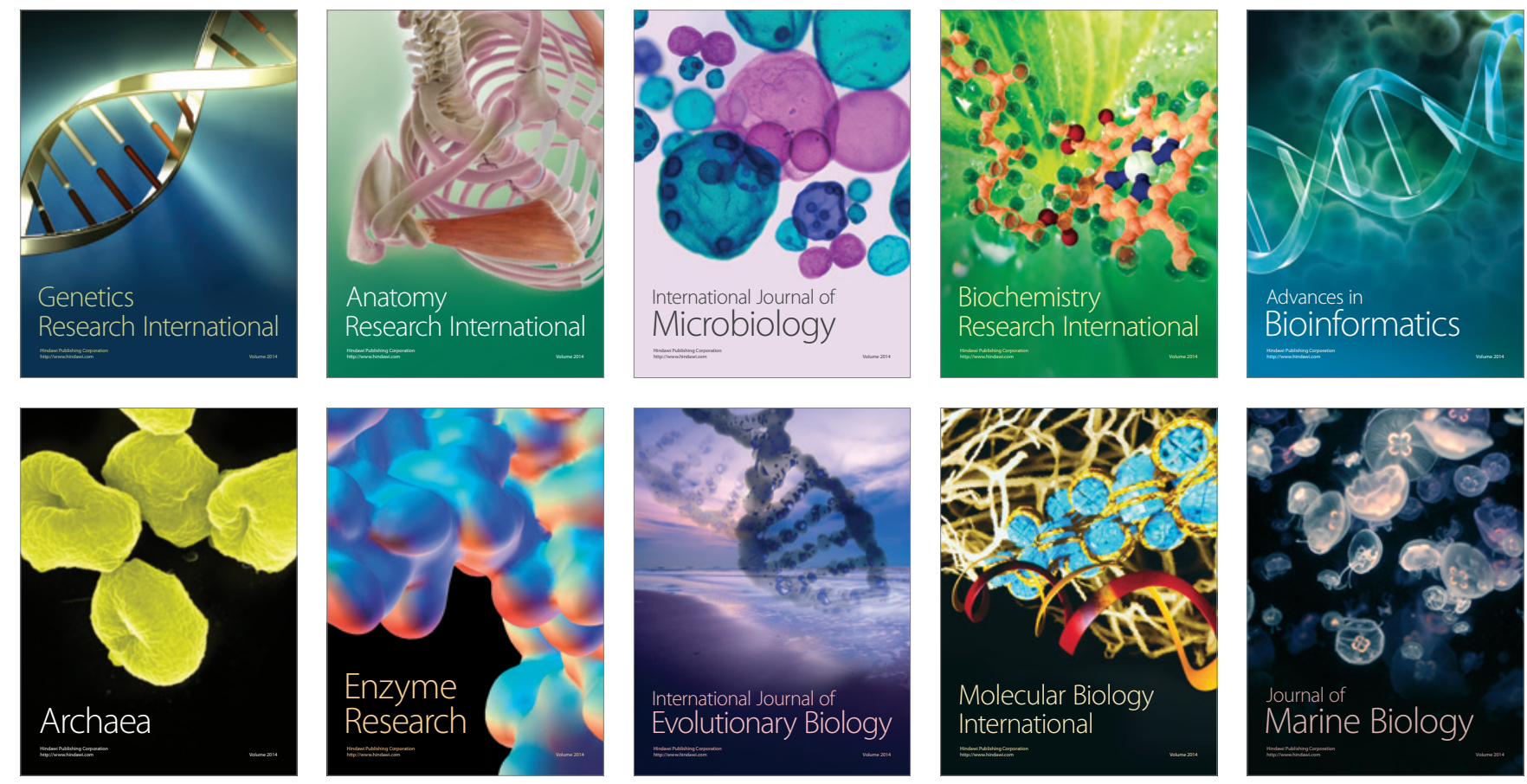